\title{
Assessing the feasibility of impregnating phase change materials in lightweight aggregate for development of thermal energy storage systems
}

\author{
Mohammad Kheradmand ${ }^{\mathrm{a}, 1}$, João Castro-Gomes ${ }^{\mathrm{b}, *}$, Miguel Azenha ${ }^{\mathrm{c}, 2}$, Pedro D. Silva ${ }^{\mathrm{d}, 3}$, \\ José L.B. de Aguiar ${ }^{\mathrm{a}, 4}$, Salah E. Zoorob ${ }^{\mathrm{e}, 4}$

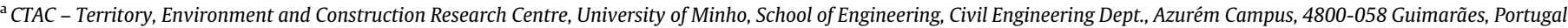 \\ ${ }^{\mathrm{b}} \mathrm{C}-\mathrm{MADE}$, Centre of Materials and Building Technologies, Department of Civil Engineering and Architecture, University of Beira Interior, 6201-001 Covilhã, Portugal \\ ' ISISE - Institute for Sustainability and Innovation in Structural Engineering, University of Minho, School of Engineering, Civil Engineering Dept., Azurém Campus, \\ 4800-058 Guimarães, Portugal \\ ${ }^{\mathrm{d}}$ C-MADE, Centre of Materials and Building Technologies, Department of Electromechanical, University of Beira Interior, 6201-001 Covilhã, Portugal \\ ${ }^{\mathrm{e}}$ Highway Materials, Universiti Teknologi Petronas, Civil Engineering Department, 31750 Tronoh, Perak, Malaysia
}

\section{H I G H L I G H T S}

- Feasibility of PCMs incorporation/encasement in LWAs.

- Leakage of impregnated/encased PCMs in LWAs under freeze/thawing test.

- Leakage of impregnated/encased PCMs in LWAs under drying test.

- SEM microstructural assessment of waterproof bound in LWAs.

\section{A R T I C L E I N F O}

\section{Article history:}

Received 7 December 2014

Received in revised form 9 March 2015

Accepted 21 April 2015

\section{Keywords:}

Phase change materials

Lightweight aggregates

Impregnation/encasement

Freeze/thawing test

Drying test

\begin{abstract}
A B S T R A C T
This paper assesses the feasibility of impregnation/encasement of phase change materials (PCMs) in lightweight aggregates (LWAs). An impregnation process was adopted to carry out the encasement study of two different PCMs in four different LWAs. The leakage of the impregnated/encased PCMs was studied when they were submitted to freeze/thawing and oven drying tests, separately. The results confirmed that, the impregnation/encasement method is effective with respect to the large thermal energy storage density, and can be suitable for applications were PCMs cannot be incorporated directly such as asphalt road pavements.
\end{abstract}

(c) 2015 Elsevier Ltd. All rights reserved.

\section{Introduction}

Phase change materials (PCMs) are used as thermal storage systems for assisting thermal control, as a consequence of their ability

\footnotetext{
* Corresponding author. Tel.: +351 275329 990; fax: +351 275329969 .

E-mail addresses: mohammadkheradmand@hotmail.com (M. Kheradmand) castro.gomes@ubi.pt (J. Castro-Gomes), miguel.azenha@civil.uminho.pt (M. Azenha),dinho@ubi.pt (P.D. Silva), aguiar@civil.uminho.pt (J.L.B. de Aguiar), salah.zoorob@googlemail.com (S.E. Zoorob).

1 Tel.: +351 913542324; fax: +351253510 217 .

2 Tel.: +351 938404554; fax: +351253510 217 .

3 Tel.: +351275329 916; fax: +351275329969

4 Tel: +351253510 206; fax: +351253510217
}

to store and release thermal energy during phase change processes (melting and freezing) [1]. During the process of solidification, PCMs release energy in the form of latent heat, and conversely, when PCMs melt, they absorb thermal energy from the surroundings. The magnitude of energy stored in a given PCM subject to certain environmental conditions strongly depends on its transition temperatures [2,3]. Many numerical and experimental investigations have been carried out in order to evaluate the incorporation of PCMs into building materials [1,4,5]. For instance, PCMs have been incorporated into plastering mortars [6,7], masonry walls [8], tiles [9], concrete [10], asphalt road layers [11] and plaster boards [12]. It is also relevant to highlight selected earlier research work that specifically focused on the incorporation of PCMs in 
asphalt road layers so as to reduce the number of freeze/thaw cycles experienced by such pavements [13-15]. In such cases, the effectiveness of PCMs for in delaying or preventing freezing was shown to be critically dependent on: ambient temperature, phase change temperature of the PCM, and thermal characteristics of the concrete or mortar in which it is incorporated. Previous studies $[13,14]$ concluded that the use of PCMs to prevent freeze/thaw cycles is a promising solution, and identified two areas that require further investigation: (1) the method of encasement used to incorporate PCMs in mortar/concrete/asphalt materials, and (2) characterizing and improving the thermal performance of the final impregnated/encased PCMs composite.

In general, thermal energy storage composites incorporating PCMs are normally fabricated via the incorporation of encased/encapsulated PCMs into porous materials without incurring any leakage of the PCMs from the final composite material. When PCMs are introduced into porous materials without being encapsulated, it becomes necessary to introduce a covering layer to seal the impregnated porous materials, in order to prevent leakage of the PCMs [16-18]. Otherwise, when the ambient temperature exceeds the melting temperature of the PCMs, the PCM can leak from the porous material and consequently jeopardize the performance of the system. Previous research has primarily focused on the preparation of shape stable encased/encapsulated PCMs [19] and/or on characterization of the thermal and mechanical properties of the composites [20,21], whilst the issue concerning PCMs leakage from porous material has not been adequately addressed. It must be stressed at this point that, possible leakage of PCMs will reduce the heat storage capacity of the composite and consequently will decrease the functionality and effectiveness of the PCMs composites [22]. Additionally, the PCM is usually organic and the presence of leaked PCM in the matrix may chemically react with it and bring deleterious effects on durability performance [23].

In this investigation, a series of composites were manufactured with different impregnated LWA types. A number of LWAs were selected possessing distinct compositions and physical properties $[13,15,24]$. The composites (impregnated/encased PCMs in LWAs) were subsequently surface coated with a number of commercial waterproofing solutions.

With the aid of multiple laboratory freeze/thaw and oven drying test cycles, accompanied by repeated mass loss measurements, the feasibility of permanent and effective encasement of PCMs in LWAs was evaluated and verified.

The present research work thus addresses the leakage potential of the impregnated/encased PCMs composites.

\section{Experimental program}

\subsection{Materials}

\subsubsection{Phase change materials}

Two types of organic PCM paraffins were considered: R3 Rubitherm RT series (melting temperature of $3{ }^{\circ} \mathrm{C}$ ) and R5 Rubitherm RT series (melting temperature of $5{ }^{\circ} \mathrm{C}$ ) [25]. The properties of the PCMs selected for this study were provided by the manufacturer [25], and are presented in Table 1. Selection of melting temperatures for the PCM's under study was based on the target application of reducing freeze-thaw cycles in pavements. Therefore, the melting temperatures were selected to be slightly above $0{ }^{\circ} \mathrm{C}$ as to attenuate the enduring of such temperature within the mortars into which the PCMs are to be applied. Furthermore, chemical compatibility with the porous materials [14] was taken into account, as well as the range of available PCMs products in the market.

\subsubsection{Lightweight aggregates}

Geometrical features of the pore structure (including porosity, pore diameter distribution, pore connectivity and pore shape) and chemical compatibility are some of the important factors to be considered when selecting porous materials for impregnation with organic PCM $[26,27]$. Four LWAs were chosen for this study, both inorganic and organic lightweight aggregates were adopted: expanded clay (IC) supplied by ARGEX - SA (Portugal) [28]; granulated expanded cork (GC)
Table 1

Properties of PCMs [25].

\begin{tabular}{llll}
\hline Materials & $\begin{array}{l}\text { Melting } \\
\text { area }\left({ }^{\circ} \mathrm{C}\right)\end{array}$ & $\begin{array}{l}\text { Density-liquid phase at } \\
15^{\circ} \mathrm{C}\left(\mathrm{kg} / \mathrm{m}^{3}\right)\end{array}$ & $\begin{array}{l}\text { Latent heat } \\
\text { capacity } \pm 7.5 \%(\mathrm{~kJ} / \mathrm{kg})\end{array}$ \\
\hline R3 & $2-5$ & 770 & 198.0 \\
R5 & $1-6$ & 770 & 180.0 \\
\hline
\end{tabular}

supplied by SOFALCA/ISOCOR Co., Ltd. [29]; expanded perlite (AP) and expanded vermiculite (EV) supplied by URBICULT Unipessoal Ltd [30]. Such materials have been considered suitable for impregnation in previous works [15,31-33]. The particle grain size distributions of LWAs was assessed with sieving method [34], and the results are presented in Fig. 1.

\subsubsection{Waterproofing materials}

Bearing in mind the importance of adequately coating the impregnated LWAs to avoid possible leakages of the PCMs, four different coating solutions were trialled (Table 2), namely: Sikalastic-490T (a polyurethane, transparent waterproofing liquid membrane) [35], Weber Dry Lastic (a liquid membrane used for waterproofing roofs) [36], Makote 3 (a waterproofing bituminous emulsion from MC-Bauchemie) [37] and ECM-2 from CEPSA (a cationic bituminous emulsion for cold asphalt mixtures) [38]. These waterproofing coating solutions need to have service temperature ranges adequate for the end applications aimed at in this research.

\subsection{Proposed procedures for encasement of PCMs and surface waterproofing}

The absorption of different PCMs paraffin waxes into different LWAs was measured in accordance with EN 1097-6 [39]. The procedure for preparation of encased thermal energy storage LWAs regardless of PCM types are shown in Fig. 2. In the first stage, all lightweight aggregates were exposed to a jet of compressed air to remove dust and any loose superficial residue from the surfaces of the particles (see Fig. 2a). The lightweight aggregates were next dried in a ventilated oven until a constant weight was achieved. The duration of drying was a minimum of $24 \mathrm{~h}$ at temperatures of $110^{\circ} \mathrm{C}, 80^{\circ} \mathrm{C}, 80^{\circ} \mathrm{C}$ and $65^{\circ} \mathrm{C}$ for the IC, AP, EV and GC respectively. The temperature adopted to dry the granulated expanded cork (GC) was slightly lower than the rest so as to cause minimal damage to the cork internal structure. It should be noted that, the imposed drying temperatures on the LWAs were adequate since each type of LWAs was monitored using an electronic moisture meter (model KERN MLB_N) and the materials was classified as dry only when the remaining moisture content was less than $1 \mathrm{mg}$ of water per $0.01 \mathrm{~kg}$ of LWA (see Fig. 2b). The LWAs were subsequently cooled down to room temperature (approx. $22{ }^{\circ} \mathrm{C}$ ) for $2 \mathrm{~h}$. Following drying, a representative sample from each LWA was completely immersed in each PCM for $24 \mathrm{~h}$ (see Fig. 2c). Impregnated LWAs samples were next drained over filter paper to remove the excess of PCM for $2 \mathrm{~h}$ at room temperature, which incidentally was above the phase change temperature (see Fig. 2d). The surfaces of the impregnated LWAs were then dried with an absorbent sheet of paper.

The impregnated LWAs were subsequently soaked with different waterproof coating solutions until the surface of the particles was fully coated. This waterproof coating procedure was also performed at room temperature, i.e., above the phase change temperature of the PCMs. Afterwards, the soaked/impregnated/waterproofed LWAs were allowed to dry in the laboratory environment (room temperature/humidity), according to the necessary drying time of each waterproofing material type, as shown in Table 2. Then, the samples were then oven dried at $60{ }^{\circ} \mathrm{C}$ for $24 \mathrm{~h}$ and were next left to dry at laboratory environment for a further 7 days. Weight variations were monitored during the entire process, and it could be confirmed that all samples had weight variations of less than 0.1 percentage during the last three days of the process, thus indicating a complete hydrothermal equilibrium state. Therefore, the product obtained at the end could be considered as emulating an industrial process of encapsulation/encasement of PCM's.

\subsection{Research program and test procedures}

In this investigation, the research program consists of three testing phases: (i) material testing; (ii) testing of PCM impregnated/encased LWAs and; (iii) performance of hardened mortar under thermal cycle loads.

\subsubsection{Material testing}

2.3.1.1. LWAs testing. In the first phase of material testing, each type of non-impregnated LWAs (IC, AP, EV and GC) was submitted to the following tests in order to characterize their capacity for impregnation: (1) density analysis, (2) pore structure analysis and (3) absorption amount test.

With respect to particle density testing, a total of 12 LWA specimens were analyzed for saturated surface dry density and the results compared to the LWAs dry density values. Particle density testing consisted of 4 representative samples from each LWAs system (IC, AP, EV or GC) with 3 repeating specimens from each LWA. Particle density determination was carried in accordance with EN 1097-6 [39]: (i) 


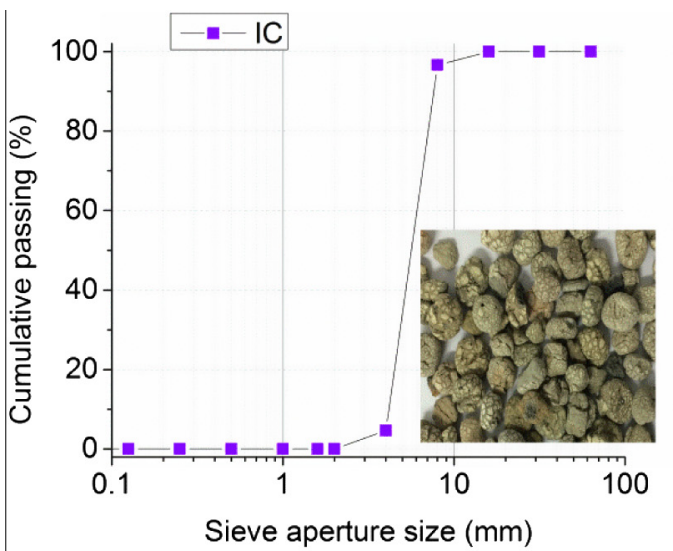

(a)

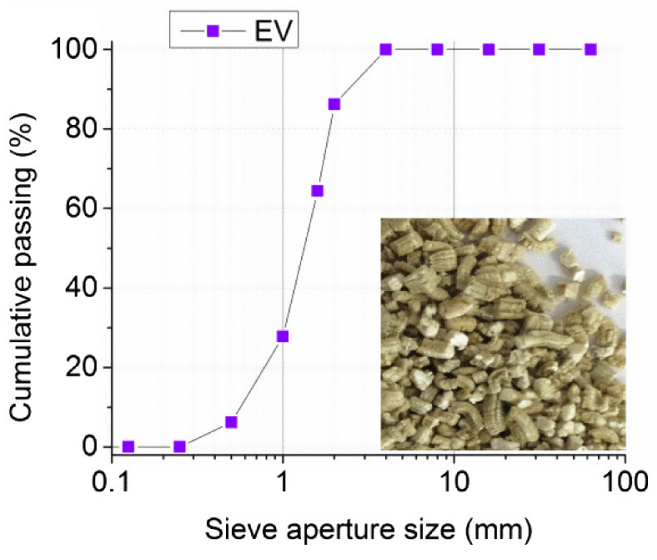

(c)

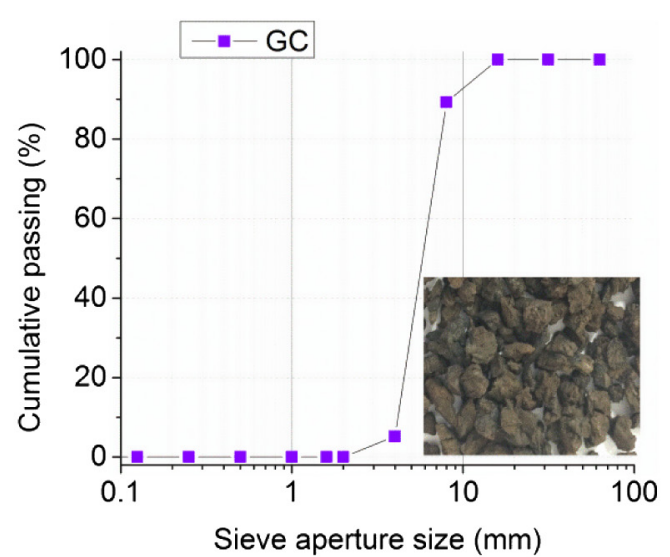

(b)

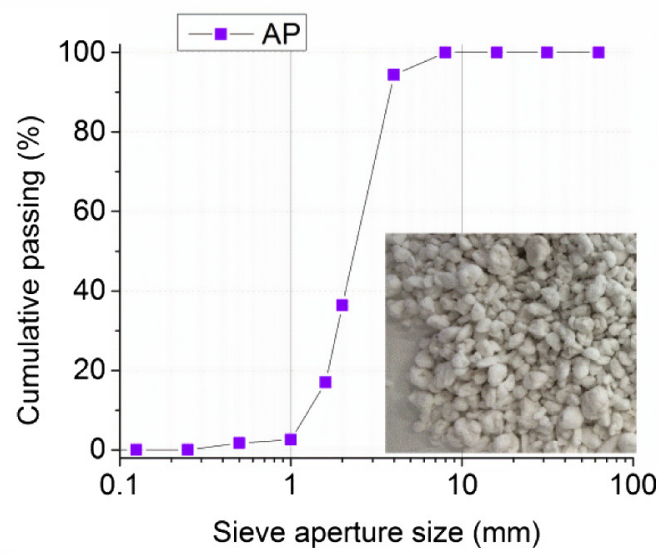

(d)

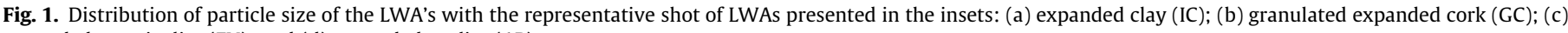
expanded vermiculite (EV); and (d) expanded perlite (AP).

Table 2

Technical data of waterproofing materials [35-38].

\begin{tabular}{|c|c|c|c|c|c|c|c|}
\hline Materials & $\begin{array}{l}\text { Application } \\
\text { temperature }\left({ }^{\circ} \mathrm{C}\right)\end{array}$ & $\begin{array}{l}\text { Service } \\
\text { temperature }\left({ }^{\circ} \mathrm{C}\right)\end{array}$ & $\begin{array}{l}\text { Softening } \\
\text { temperature }\left({ }^{\circ} \mathrm{C}\right)\end{array}$ & Density (kg/m3) & Drying time (h) & Color & Names \\
\hline CEPSA (ECM-2) & $30-60$ & - & +35 & - & - & Black & CEP \\
\hline MC-Bauchemie (Makote 3) & $5-40$ & * & - & 1080 & 48 & Black & MCB \\
\hline Weber Dry Lastic & $10-40$ & -15 to +70 & - & 1300 & $24-36$ & White & WEB \\
\hline Sikalastic-490T & $5-40$ & -30 to +90 & - & 990 & $8-12$ & Transparent & SIK \\
\hline
\end{tabular}

${ }^{*}$ No information available on behalf of the supplier. The product is a bituminous emulsion that is recommended for protection of buried concrete elements or as a primer for asphaltic fabric.

first, LWAs samples were oven-dried at $80^{\circ} \mathrm{C}$ for $24 \mathrm{~h}$; (ii) then, LWAs samples were next immersed in water at $22^{\circ} \mathrm{C}$; (iii) following water immersion, LWAs samples were placed on filter paper for $2 \mathrm{~h}$ at room temperature (about $22^{\circ} \mathrm{C}$ ) to drain the excess of superficial water; (iv) then, the surface of the samples was dried with an absorbent sheet of paper. Finally the surface dried LWAs samples were placed inside various densimeter of $500 \mathrm{~mL}$ capacity and weighted.

Pore structure analysis was also conducted on 12 specimens comprising 4 representative samples of each LWAs system (IC, AP, EV or GC) with 3 repeat specimens from each LWA type.

Specific total surface area and pore size distribution of the LWAs were measured using a Quantachrome Instrument, model NOVA 2200e.

Total specific surface area (external surface area and pore surface of particles) determinations were conducted using Multi-point Brunauer-Emmett-Teller (B.E.T) method which is suitable for solid materials [40]. Furthermore, the Barrett, Joyner and Halenda's (B.J.H) method was used to determine pore size distribution, which relates pore volume to pore size, also allowing porosity analysis. In this test nitrogen was used for adsorption and desorption processes with an accuracy of $\pm 0.1 \%$ and liquid nitrogen was used to maintain a controlled environment.
Also in this phase, a series of tests ( 24 specimens) have been performed to assess the absorption capacity of PCMs by the LWAs selected for this investigation. This included 8 representative specimens of each LWA type (IC, AP, EV or GC) with each type of PCM (R3 or R5) with 3 repeating specimens from each mixture. Specific nomenclature has been given to each composite material in order facilitate identification. In this way a designation type was created in which the two first characters stand for the name of the corresponding LWA (IC, AP, EV or GC), followed by two characters corresponding to the PCMs type (R3 or R5).As an example, IC_R3 corresponds to expanded clay containing PCM with melting temperature of $3^{\circ} \mathrm{C}$.

2.3.1.2. PCM testing. Also in this phase of material testing, both PCM types (i.e. R3 and R5) were subjected to differential scanning calorimetry (DSC) testing. One DSC experiment was conducted for each of the studied PCMs.

The DSC calorimeter submits the pure PCM sample to controlled temperatures and records the corresponding heat fluxes, thus providing information about temperatures and specific enthalpies associated with phase changes. Based on the measured heat fluxes corresponding to heating or cooling processes, the specific heat, as 


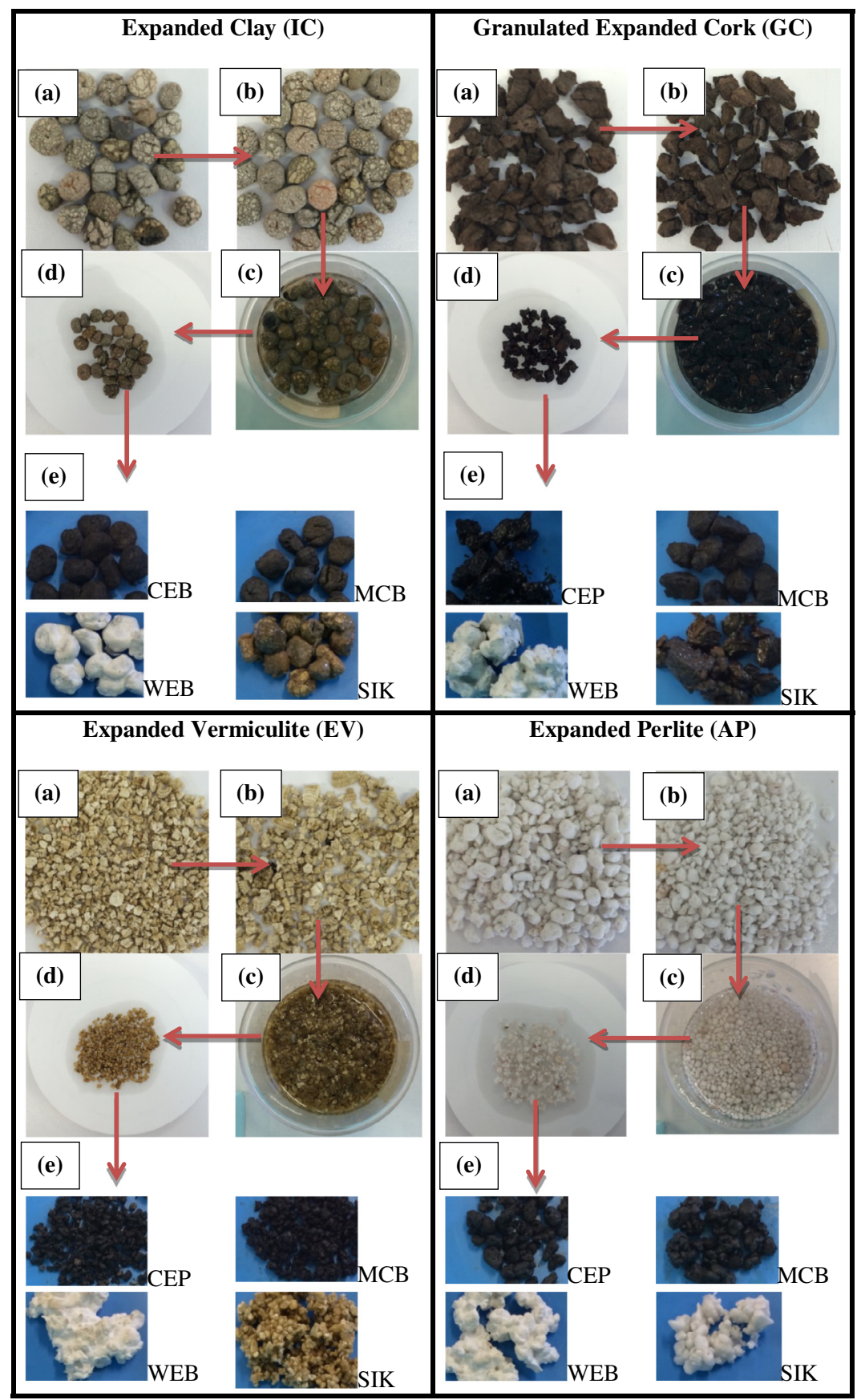

CEP: Is the waterproof material with the name of CEPSA (ECM-2);

MCB:Is the waterproof material with the name of MC-Bauchemie (Makote 4);

WEB:Is the waterproof material with the name of Weber Dry Lastic;

SIK:Is the waterproof material with the name of Sikalastic -490T.

Figure 2 - Illustration of encased/encapsulated thermal energy storage LWAs (a) cleaned surfaces of the particles after using a jet of compressed air; (b) dried LWAs following removal from a ventilated oven; (c) impregnation of LWA in PCM; (d) drainage procedure over a filter paper (e) visual appearance of PCM+LWA samples coated with different waterproofing materials.

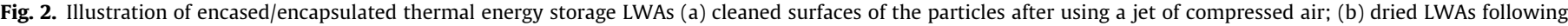

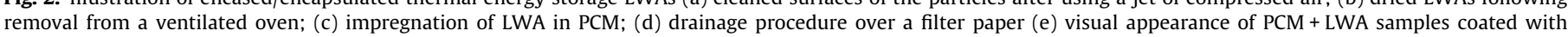
different waterproofing materials.

a function of temperature, can be obtained, and the specific enthalpy is determined by numerical integration procedures [41]. In this study, the methodology of specific enthalpy calculation follows the strategy adopted in [42]. The melting and freezing behaviors of the PCM were analyzed by a DSC model NETZSCH 200 F3 Maia. The DSC has an accuracy of $\pm 0.2^{\circ} \mathrm{C}$ for temperature measurements.

All the samples were tested in $40 \mu \mathrm{L}$ capacity aluminum crucibles under nitrogen $\left(\mathrm{N}_{2}\right)$ atmosphere with a flow of $50 \mathrm{~mL} \mathrm{~min}{ }^{-1}$. The weights for samples R3 and R5 were $5.35 \mathrm{mg}$ and $5.68 \mathrm{mg}$ respectively, measured to an accuracy of $\pm 0.01 \mathrm{mg}$. Each sample was sealed in the pan by using an encapsulating press. An empty aluminum crucible was used as a reference in all measurements.

The effect of thermal cycles and heating/cooling rates on the phase change processes and specific enthalpy values was examined. In this way, different heating/cooling rates of $0.5^{\circ} \mathrm{C} \mathrm{min}^{-1}, \quad 1^{\circ} \mathrm{C} \mathrm{min}^{-1}, 2{ }^{\circ} \mathrm{C} \mathrm{min}^{-1}, 5{ }^{\circ} \mathrm{C} \mathrm{min}{ }^{-1}$ and $10^{\circ} \mathrm{C} \mathrm{min}^{-1}$ were considered. The applied program steps for the test procedure of samples were as follows: (i) initial isothermal period at $-20^{\circ} \mathrm{C}$ for $5 \mathrm{~min}$; (ii) 
dynamic heating up to $+20^{\circ} \mathrm{C}$ according to the proposed rate $\left(0.5^{\circ} \mathrm{C} \mathrm{min}^{-1}\right.$, $1{ }^{\circ} \mathrm{C} \min ^{-1}, 2^{\circ} \mathrm{C} \mathrm{min}^{-1}, 5^{\circ} \mathrm{C} \mathrm{min}^{-1}$ or $10^{\circ} \mathrm{C} \mathrm{min}^{-1}$ ); (iii) stabilization at $+20^{\circ} \mathrm{C}$ for $5 \mathrm{~min}$; (iv) dynamic cooling to $-20^{\circ} \mathrm{C}$ with proposed rate $\left(0.5^{\circ} \mathrm{C} \mathrm{min}{ }^{-1}\right.$, $1{ }^{\circ} \mathrm{C} \min ^{-1}, 2{ }^{\circ} \mathrm{C} \mathrm{min}{ }^{-1}, 5^{\circ} \mathrm{C} \mathrm{min}^{-1}$ or $10^{\circ} \mathrm{C} \mathrm{min}^{-1}$ ). For the PCMs analyzed, each sample endured one full cycle (each full cycle consisted of the steps (i)-(iv) as detailed earlier). The DSC peaks for each PCM were evaluated for a cycle of heating/cooling curves in terms of latent heat storage and phase change temperatures, in line with Refs. [43-45]. The onset and end temperature for each transition were determined in accordance with standard EN ISO 11357-1[46].

\subsubsection{Testing of PCM impregnated/encased LWAs}

In this phase, two series of tests were performed on PCM impregnated/encased LWAs: freeze/thaw cycle tests and drying tests.

A total of 40 specimens were tested under freeze/thaw cycles. This included 8 representative specimens from each LWAs system (IC, AP, EV or GC) with each type of PCM (R3 or R5) with or without a waterproofing solution (REF, SIK, WEB, MCB or CEP). Additionally a total of 40 specimens (same distribution as used for the freeze/ thaw cycles) were tested by oven drying. Specific nomenclature has been given to each composite material in order facilitate identification. In this way a designation type was created in which the first two characters stand for the name of corresponding LWAs (IC, AP, EV or GC), the following two characters correspond to the PCMs type (R3 or R5), and the last three characters represents the type of water proofing solution (REF, SIK, WEB, MCB or CEP). For samples with no waterproofing layer, the three letters "REF" stands for reference material. As an example, the IC LWA impregnated with R3 and waterproofed with the Sika product is termed IC_R3_SIK. Conversely, the corresponding impregnated LWA without waterproofing is termed IC_R3_REF.

Reference and waterproof-coated specimens were left at room temperature for 7 days curing, prior to conducting the freeze/thawing tests. The freeze/thaw temperature range was selected to be between $-7^{\circ} \mathrm{C}$ and $+16^{\circ} \mathrm{C}$. This range is slightly larger than the range of temperatures that is recorded during Winter in Portugal, particularly in the mountain regions of Guarda [47].

To carry out the experiments, four sets of specimens were used. Each set contained five particles of different types of encased PCMs with and without waterproofing coating. At the start of each test, the initial weight of the specimens was recorded. Specimens were next exposed to 3 freeze/thaw cycles (1 cycle consisting of $0.25 \mathrm{~h}$ of freezing in air inside an automatic conventional freezer, followed by $1.5 \mathrm{~h}$ of thawing in water). Each specimen was subsequently weighed at the conclusion of the third cycle, thus monitoring the process of desiccation.

A dimensionless parameter $S$ has been introduced to evaluate the effect of freeze/thaw cycles on the percentage of mass loss, as follows (Eq. (1)):

$S=\frac{\Delta w}{w_{0}} \times 100 \%$

where the $\Delta w$ is increment of water content measured in the frozen/thawed composite after three cycles, and $w_{0}$ is the water content in the unfrozen/unthawed composite.

To measure the ability of PCM to impregnate LWA, a drying test was adopted according to Ref. [13]. In this test the specimens were first weighed and then placed in an oven at $40{ }^{\circ} \mathrm{C}$, and repeatedly weighed with at least $24 \mathrm{~h}$ intervals between measurements for at least seven days thereafter. Since, the waterproofing materials include water contents and will influence the correct measurement of the leaked PCM from LWAs, separate drying tests were performed on the waterproofing materials themselves. The water content in each waterproofing material was determined by placing a few grams of waterproofing material in an oven and conducting a drying test (following a similar test procedure as mentioned earlier for impregnated encased LWAs). The average amount of PCM retained by the aggregate was considered the impregnation capacity of the LWA in regard to the amount of the water loss of waterproofing materials. Any residue remaining on the surface of the aggregates was only quantified with visual observations of whether the aggregate appeared wet or dry. Similar methodology has been attempted in terms of number of specimens, consideration as freeze/thawing test.

\section{Results and discussion}

\subsection{LWA testing results}

Dry and water saturated LWAs particle density results, as well as percentages masses of water absorption of LWAs, are presented in Fig. 3. The saturated density difference between the four LWAs is related with the volume of existing voids that can be filled in with water. As it can be seen from the results, the EV has the highest saturated particle density (see Fig. 3a), which means it can absorb the highest amount of water in open pores when compared to the other LWAs studied in this work, as seen in Fig. 3b. The density of saturated LWAs increased by 1.22, 1.64, 6.72 and 2.83 times when compared with dry densities, for IC, GC, EV and AP respectively. This indicates that the amount of water penetrating the open pores (water absorption) of LWAs are different, for example, the EV particles absorbed much more water than other LWA materials and have higher open porosity.

It is important to note that the absorption characteristics of an aggregate can also depend on the aggregate size. Large lightweight aggregate have larger voids (like IC and GC). As a result, these large pores effectively become part of the texture of the aggregate, and they are thus no longer considered as internal porosity in the aggregate [48]. Comparison between the studied LWAs reveals that, smaller particles (like EV and AP) tend to have grater total porosity simply because they have expanded to a greater extent than a larger particle. Therefore, in the tested LAWs using different size particles it was observed that the absorption of the smaller aggregate particle sizes was higher than the absorption of larger particles.

These results give adequate information regarding the pore volume of the studied LWAs.

The pore size distributions of IC, GC, AP and EV, analyzed according to Section 2.3.1, are shown in Fig. 4. The figure presents the LWAs pore size distribution in terms of log differential intrusion volume in $d V / d \log (r)$, where $V$ is the volume intruded into the pores of the sample. The log differential intrusion volume is

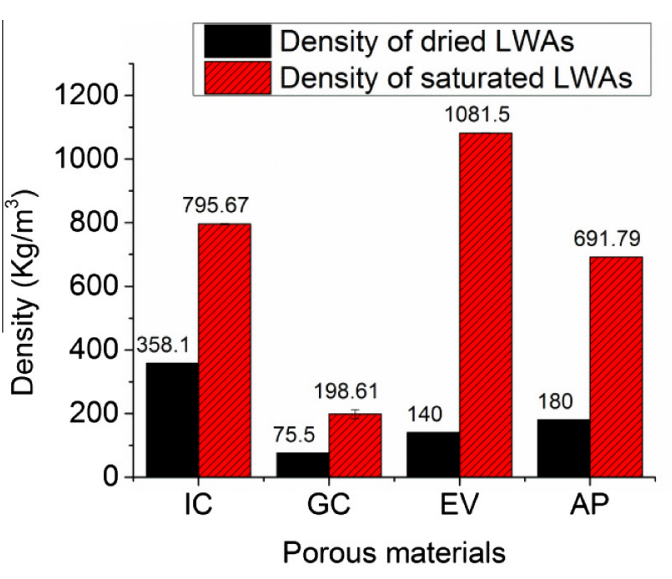

(a)

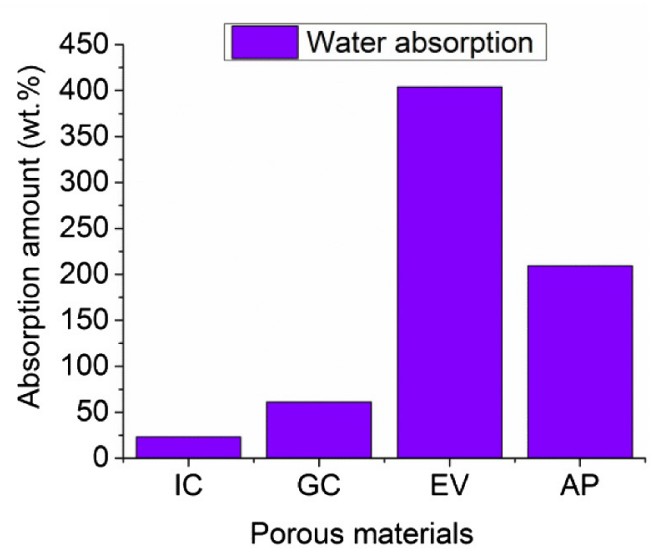

(b)

Fig. 3. (a) Density comparison between dried and water saturated LWAs; (b) percentage of mass water absorption of the porous materials. 


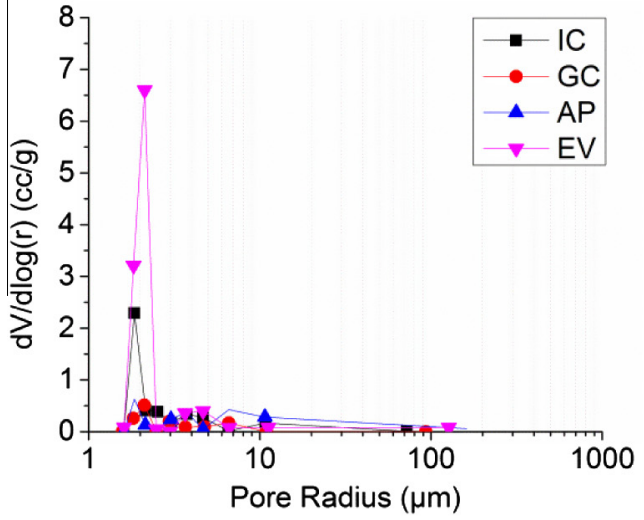

(a)

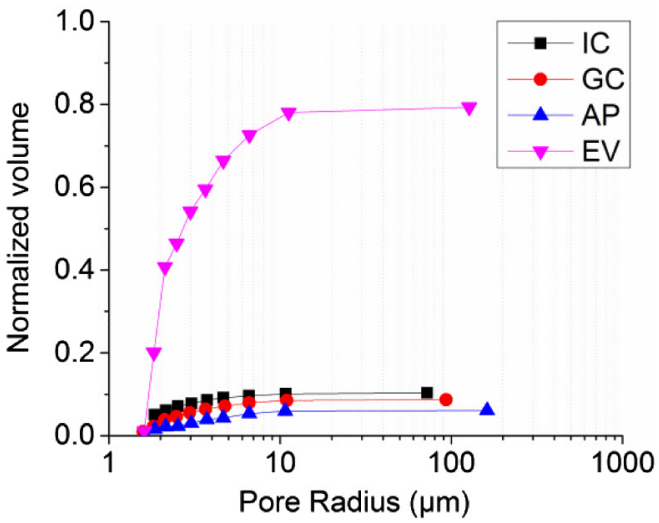

(b)

Fig. 4. Pore size distribution of IC, GC, AP and EV: (a) differential curves; (b) cumulative curves.

the derivative of the intruded volume. The derivative plots show clearly identified points of inflection, which highlight zones where clusters of pores of a particular radius occur. Fig. 4b, depicts the relative distribution of each LWA in terms of the cumulative intruded pore volume to the weight of the sample.

As shown in Fig. 4a, EV LWAs have more volume of pores per unit weight when compared with the other LWA materials. The strong peak indicated that most pores have approximately $2.1 \mu \mathrm{m}$ radius, for the EV. On the other hand, IC, GC and AP have less volume of pores, having approximately $1.9 \mu \mathrm{m}$ of radius. According to the International Union of Pure and Applied Chemistry (IUPAC) pore-size classification [49], which classifies pores into macro, meso and micropores, the pores of the IC and EV LWAs are mesopores, as they are larger than $2 \mu \mathrm{m}$. Furthermore, GC and AP LWAs have micropores since sizes are lower than $2 \mu \mathrm{m}$.

The total specific surface areas per unit mass values were 0.321 $\left(\mathrm{m}^{2} / \mathrm{g}\right), 0.188\left(\mathrm{~m}^{2} / \mathrm{g}\right), 5.817\left(\mathrm{~m}^{2} / \mathrm{g}\right)$ and $0.437\left(\mathrm{~m}^{2} / \mathrm{g}\right)$ for IC, GC, EV and AP, respectively. The EV has much larger total specific surface area than other LWAs. The results of pore size analysis are coherent with previous information regarding the capacity to absorb water, which indirectly indicated the porosities (see Fig. 3). Consequently, the pore structure plays an important factor in the absorption capacity of the LWAs. The LWAs with greater pore volumes and larger pore radiuses are bound to be capable of absorbing higher water or paraffin content. Nevertheless, it should be noted that, the viscosity of paraffin and water are slightly different, and also that the corresponding surface tension properties and hence impregnation potential can also be different.

\subsection{PCM absorption in LWAs}

The results of absorption amounts of both R3 and R5 PCMs into the four different LWAs are presented in Fig. 5. Comparing these results to the water saturated density test results (Fig. 3), the data shows that the PCMs (R3 or R5) absorption is not reaching the maximum possible absorption of water.

It is interesting to highlight the quantitative differences between the capacity of absorption of water and PCM into LWAs. For instance, IC, EV and AP displayed water absorption values higher by $21 \%, 55 \%$ and $52 \%$ (wt.\%) respectively compared to the cases with R3 absorption. In the case of GC the water absorption (wt.\%) was about 7\% less than that obtained with R3. However, it should be noted that, there is a slight difference in PCM absorption (wt.\%) between LWAs types GC, EV and AP absorbed 5\%, 10\% and $23 \%$ more $\mathrm{R} 4$ respectively than the absorption values for R3.
These differences in absorption volume may be attributed to the differences in PCMs specific gravity, viscosity, and liquid surface tension.

It can be clearly observed that the absorption amounts with different LWAs follow the same trend. The absorption amounts for IC was generally lower than that for the GC, EV and AP, possibly due to the more homogenous (narrow particle size distribution of the IC particles). For the EV mixes with PCMs types R3 and R5, the increments were about 290 wt.\% and 240 wt.\% respectively. In fact, the EV particles contain both types of meso and micropores when compared to the other three kinds of LWAs. However, the impregnate of liquid part into the pore space of LWAs with smaller diameter becomes more difficult than those with larger diameter. Therefore, the adopted impregnation method may be more appropriate to porous materials that encompass both micro and meso pores.

Overall, the results showed that the total amount of PCM absorbed in each LWA is very high. It is interesting to have a comparison between the global quantities of PCMs that can be introduced into the mix by impregnation technique and the classical way of incorporating commercially microencapsulated PCM.

Consider the case of a cement based mortar incorporating with commercial microencapsulated PCM that was formulated by the authors [42]. This mortar, referred to as SPCMM24 contained $293 \mathrm{~kg}$ of microencapsulated PCM per cubic meter, whereas, the impregnation technique used in this investigation allows for up to a maximum PCM content of about $213 \mathrm{~kg} / \mathrm{m}^{3}$ when using the EV aggregate. This is not a significantly lower PCM content, and is therefore, not necessarily a problem as it is approximately within the same order of magnitude, but at a fraction of the cost of the microencapsulated PCM. With respect to LWA types IC, GC and $\mathrm{AP}$, the impregnation technique used in this investigation allows for a maximum PCM content of about $49 \mathrm{~kg} / \mathrm{m}^{3}, 109 \mathrm{~kg} / \mathrm{m}^{3}$, and $171 \mathrm{~kg} / \mathrm{m}^{3}$ respectively.

\subsection{PCM testing results}

\subsubsection{General remarks}

In order to quantify the thermal energy storage capacity of the PCMs, differential scanning calorimetry (DSC) was deployed. In view of the acknowledged dependency of DSC results on the heating/cooling rates [50,51], the assessment of the influence of heating/cooling rates on the DSC thermograms as well as specific enthalpy calculation has been analyzed and separated into two main sections: (1) effect of the heating/cooling rates; (2) specific enthalpy analysis. 


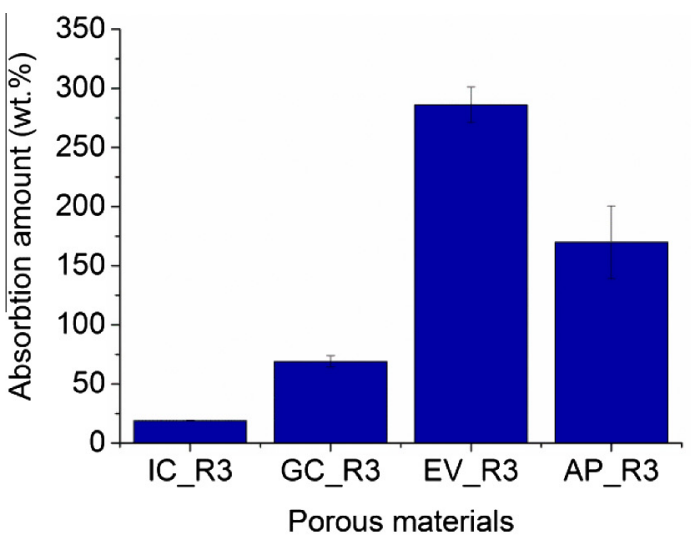

(a)

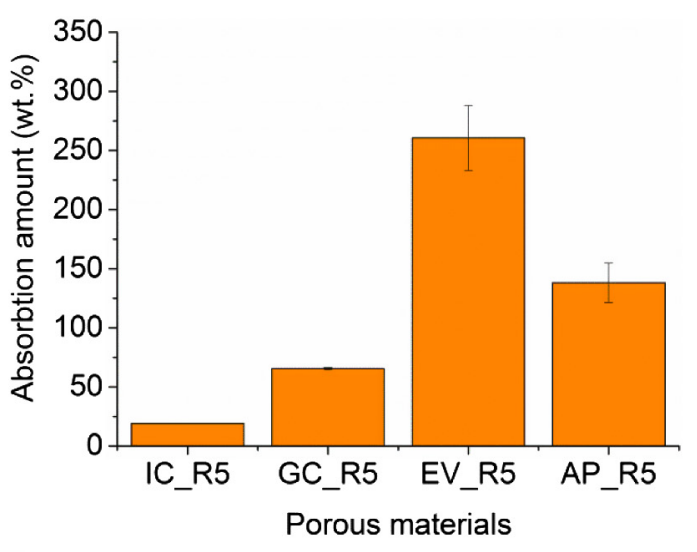

(b)

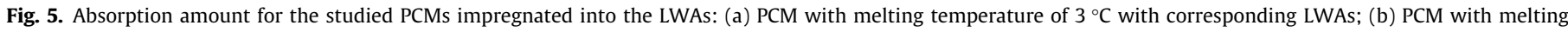
temperature of $5^{\circ} \mathrm{C}$ with corresponding LWAs.

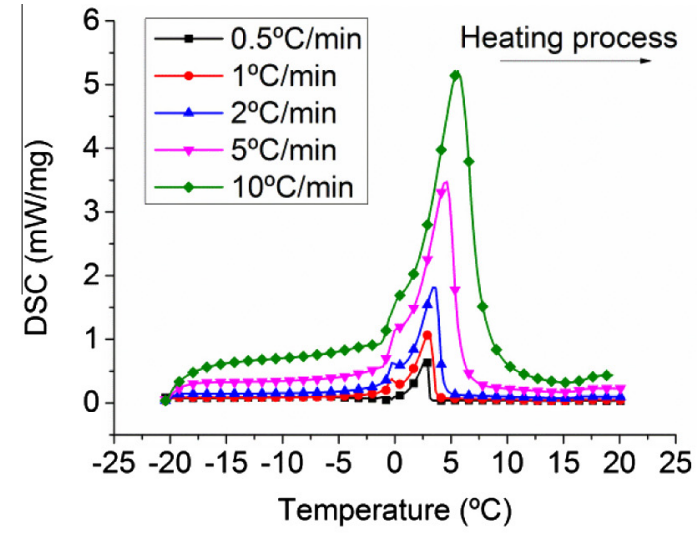

(a)

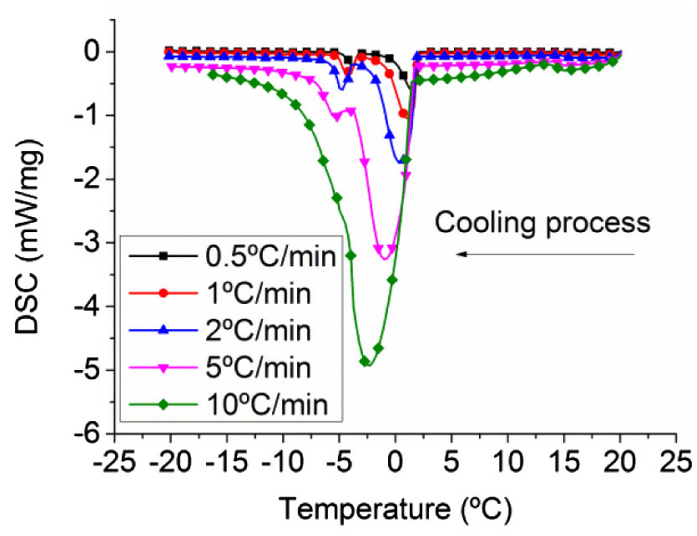

(b)

Fig. 6. DSC thermograms for R3 specimen with different heating/cooling rates: (a) heating process at several rates; (b) cooling process at several rates.

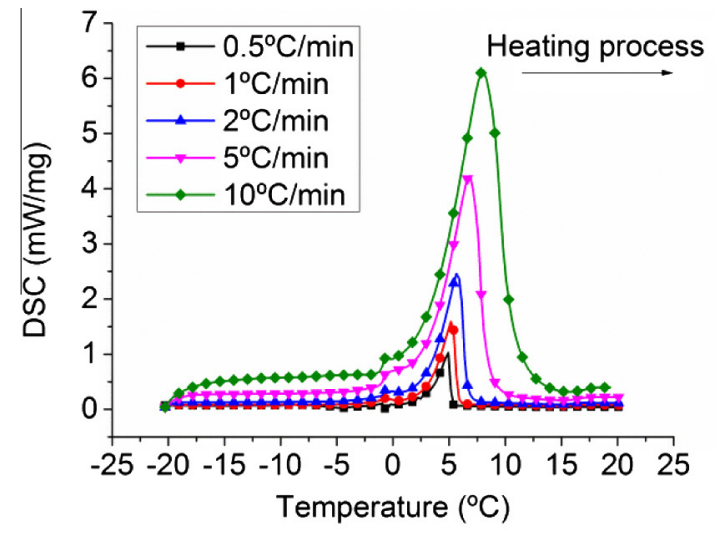

(a)

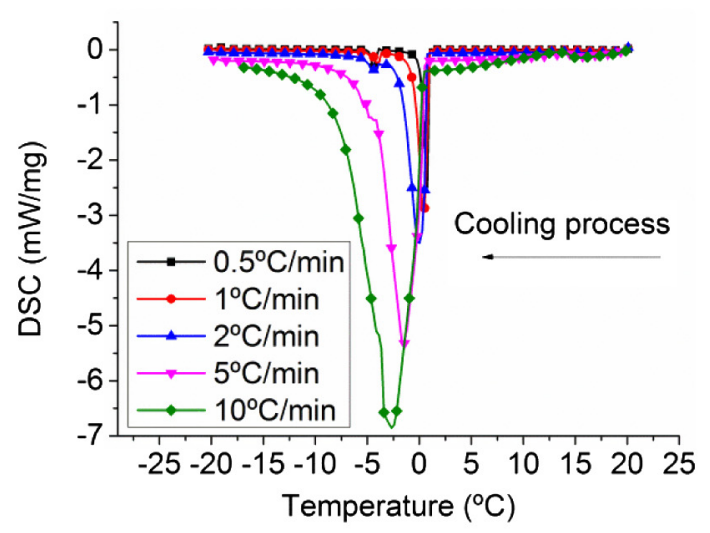

(b)

Fig. 7. DSC thermograms for R5 specimen with different heating/cooling rates: (a) heating process at several rates; (b) cooling process at several rates.

\subsubsection{Effect of the heating/cooling rates}

The experimental curves for R3 at different heating/cooling rates are shown in Fig. 6. The peak temperatures in the thermograms of the heating process (Fig. 6a) are consistently being increased as the heating rate increases. Conversely, in the case of cooling (Fig. 6b), the peak temperatures decreases with increased cooling rates. Overall, it was observed that the PCM peak response shifts in the direction of the imposed flux; i.e. higher peaks for heating and lower peak temperatures for cooling. This type of behavior has been reported in earlier investigations [52] and [53], and it can be explained by an increasing thermal gradient in the sample. 


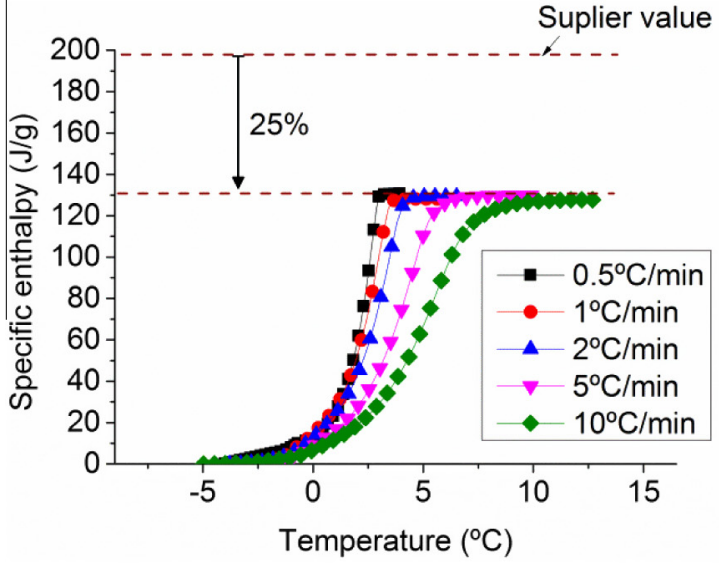

(a)

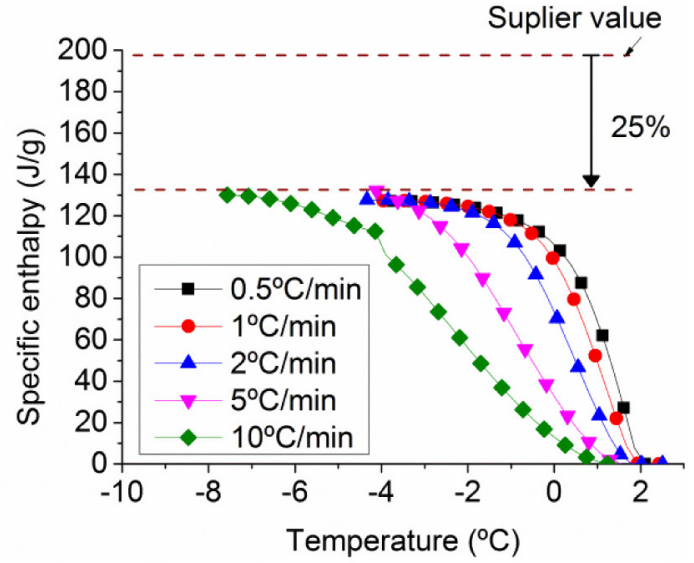

(b)

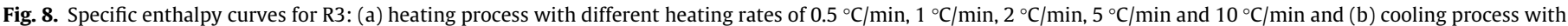
different heating rates of $0.5^{\circ} \mathrm{C} / \mathrm{min}, 1^{\circ} \mathrm{C} / \mathrm{min}, 2^{\circ} \mathrm{C} / \mathrm{min}$ and $5^{\circ} \mathrm{C} / \mathrm{min}, 10^{\circ} \mathrm{C} / \mathrm{min}$.

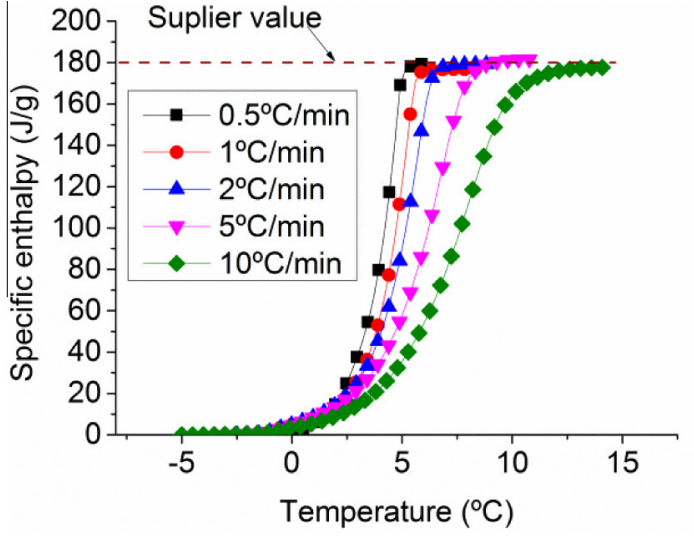

(a)

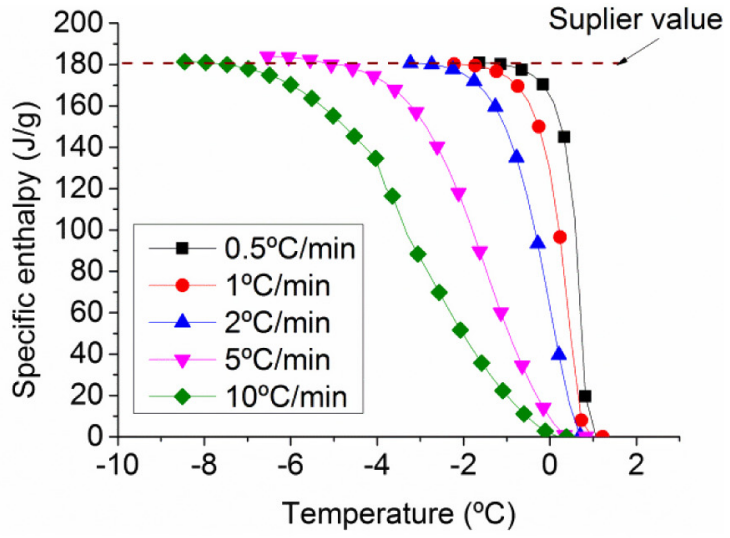

(b)

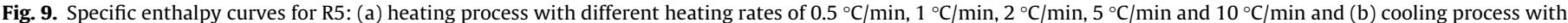
different heating rates of $0.5^{\circ} \mathrm{C} / \mathrm{min}, 1^{\circ} \mathrm{C} / \mathrm{min}, 2^{\circ} \mathrm{C} / \mathrm{min}, 5^{\circ} \mathrm{C} / \mathrm{min}$ and $10^{\circ} \mathrm{C} / \mathrm{min}$.

The DSC curves for the R5 specimen at several heating and cooling rates are shown in Fig. 7. The observations are quite similar to those already made for R3, except for the fact that this new PCM (R5) exhibits shifted phase transition in terms of peak temperatures compared to R3.

It is interesting to note that, for samples R3 and R5, at a heating rate of $2{ }^{\circ} \mathrm{C} / \mathrm{min}$, the phase change melting temperatures were in direct agreement with those specified by the material supplier (see Table 1).

\subsubsection{Specific enthalpies of PCMs}

From the DSC output, the specific enthalpy $H(T)$ is calculated for each phase transition based on equation Eq. (2):

$H(T)=\frac{1}{\varphi} \int_{T_{\text {onset }}}^{T}\left[\operatorname{DSC}(T)_{\text {sample }}-\operatorname{DSC}(T)_{\text {baseline }}\right] d T$

where DSC $(T)_{\text {sample }}$ is the value of DSC signal at temperature $T$ from the thermogram ( $\mathrm{mW} / \mathrm{mg}$ ), $\mathrm{DSC}(T)_{\text {baseline }}$ is the value of DSC signal at temperature $T$ from the baseline of the thermogram for the phase change $(\mathrm{mW} / \mathrm{mg}), \varphi$ is the heating or cooling rate $\left({ }^{\circ} \mathrm{C} / \mathrm{s}\right), T_{\text {onset }}$ is the onset temperature $\left({ }^{\circ} \mathrm{C}\right)$, and $T$ is the temperature $\left({ }^{\circ} \mathrm{C}\right)$.
The results of the calculation of specific enthalpy evolution along temperature for R3 are shown in Fig. 8a and b, which present the results of specific enthalpy for heating and cooling processes, respectively. It can be observed that the accumulated specific enthalpy is almost constant (nearly $130 \mathrm{~J} / \mathrm{g}$ ) regardless of the heating/cooling rate. However, it should be noted that, the obtained specific enthalpy for R3 has a lower value (about 25\% less) in comparison with the material supplier data.

Fig. 9 shows the specific enthalpy evolution for R5, and as expected, the accumulated enthalpy is almost independent of the heating/cooling rate. The obtained specific enthalpy value obtained for R5 (approx.180 J/g) was consistent with the information provided by the supplier (see Table 1 ).

\subsection{Effect of freeze/thaw cycles on mass loss of impregnated/coated LWAS}

From now on, for the sake of brevity, the term of "composite" will be used to address the impregnated/coated LWAs. The maximum percentage mass loss (in terms of the mass of total composite) was evaluated after concluding three freeze/thawing test cycles and the results are shown in Fig. 10. It is interesting to note that the percentage of mass loss of each composite varies with 


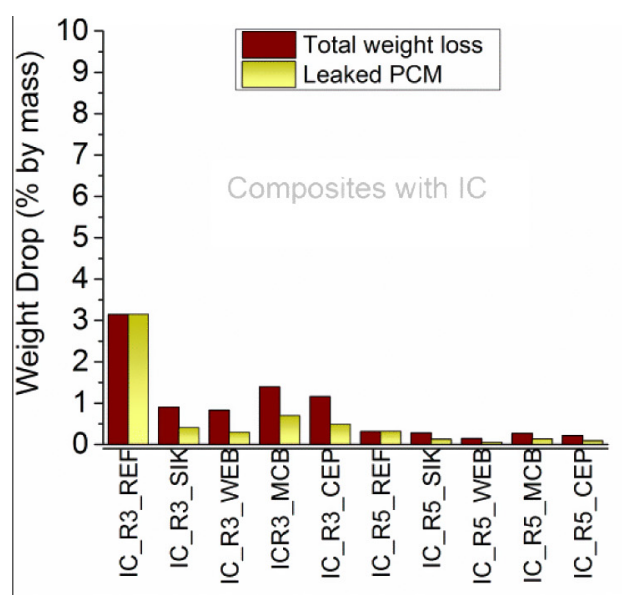

(a)

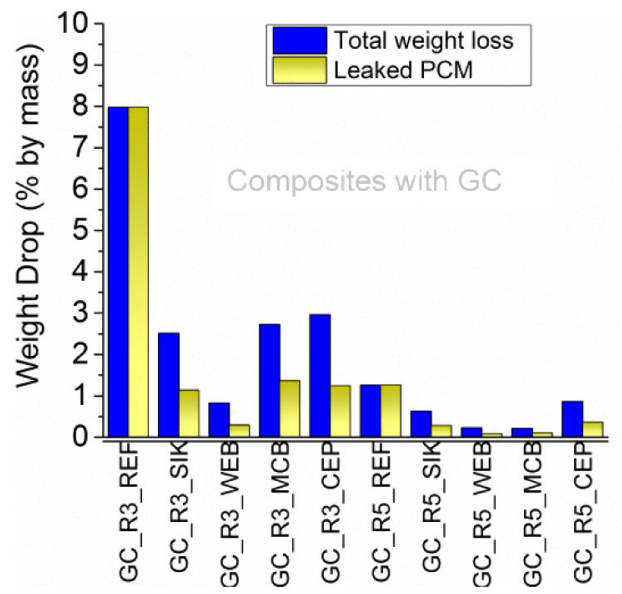

(c)

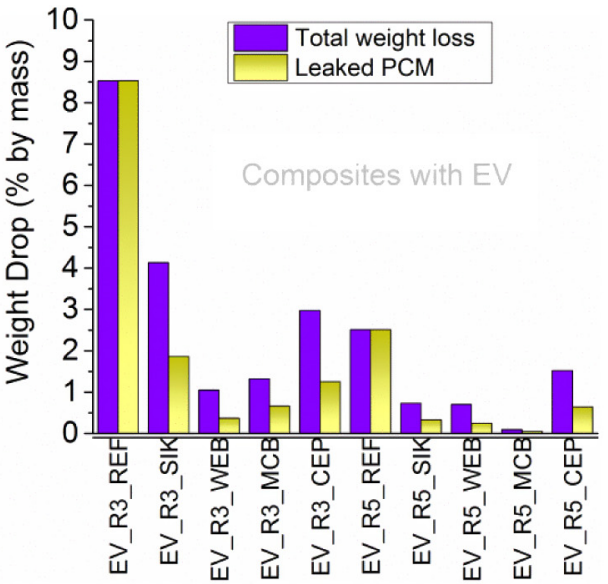

(b)

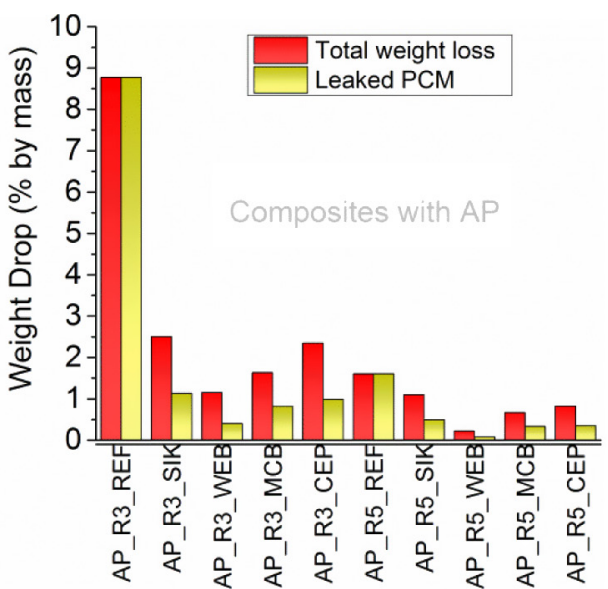

(d)

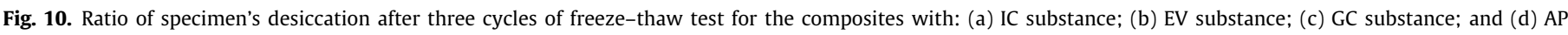
substance.

different waterproofing material. This can be explained by the fact that, the water proofing material loses weight during the freeze thawing process and its thickness is not homogeneous in each particle and LWA. Thus, the non-homogeneity of waterproofing thickness is most responsible for the mass losses discrepancies found for each different composite.

In order to illustrate the non-homogeneity of the thickness of waterproofing coating a scanning electron microscopy (SEM) study was carried on IC particles. The IC particles were mixed with a cement-based mortar, and cured for 28 days. A specimen of hardened mortar composite was then embedded in resin and surface polished for the microscopy study. The general view of the microstructure of the specimen is presented in Fig. 11, which shows a cross section of IC particles surrounded by waterproof coating. It is evident that the thickness of the waterproofing coating layer around the IC particles is not uniform.

In terms of waterproofing type effect on mass loss of the composites, a significant reduction can be observed in all composites with all four different waterproofing solutions. Taking into account weight loss of the different composites with different PCMs, the smallest value was recorded for the cases of composites with R5 (about $0.7 \%, 1.5 \%, 0.5 \%$ and $1 \%$ by mass for the composites with IC, EV, GC and AP, respectively). In contrast, the composites with R3 exhibited a greater drop in mass of about $1 \%, 2.5 \%, 2 \%$ and $2 \%$ for IC, EV, GC and AP, respectively.

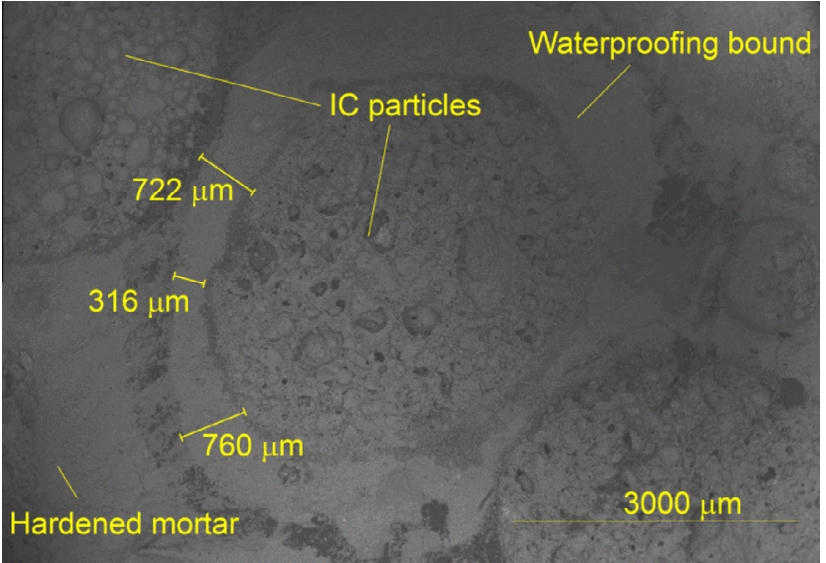

Fig. 11. SEM micrograph of the IC particle embedded in cement-based hardened mortar showing waterproofing bound thickness variation.

At this stage, the results revealed that, the influence of the porous lightweight aggregate on the development of physical property values has dependency on the waterproofing type.

The water loss percentage of the waterproofing itself was determined, and then it was subtracted from corresponding total weight loss of each composite. The results of drying test on the 


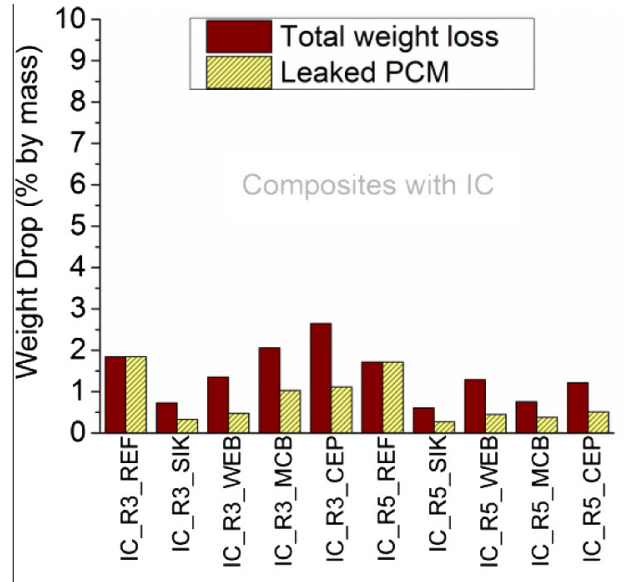

(a)

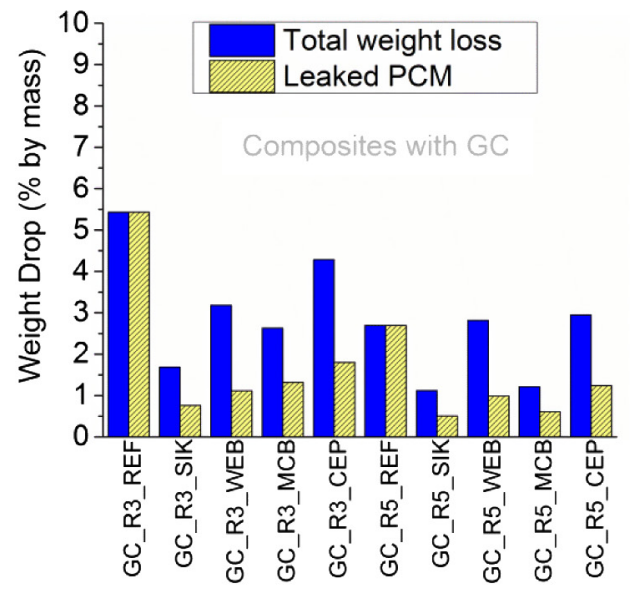

(c)

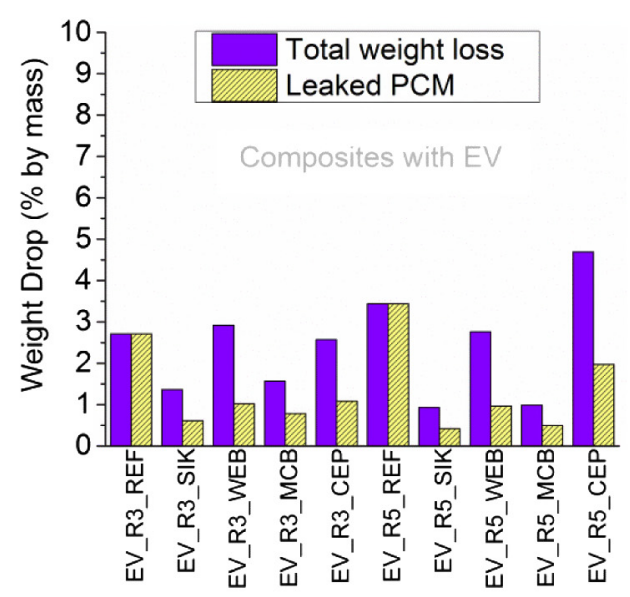

(b)

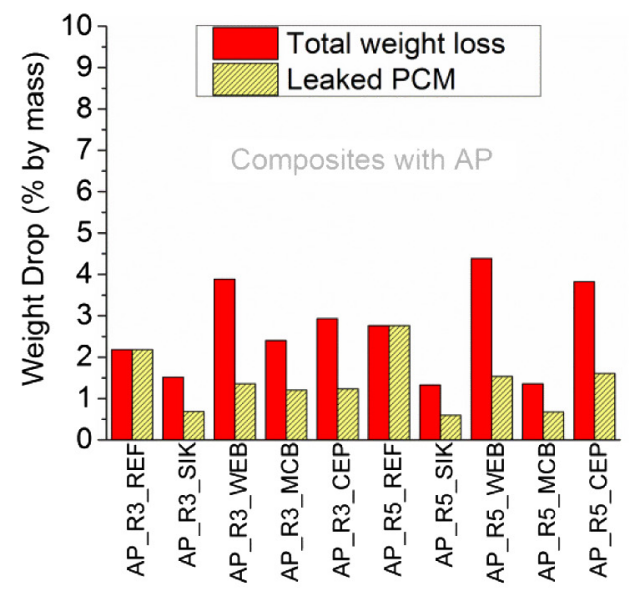

(d)

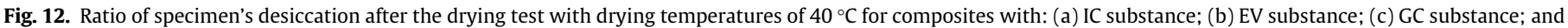
(d) EP substance.

waterproofing materials showed that the waterproofing material can lose water by $65,50,58,55$ percentage weight loss for the WEB, MCB, CEB and SIK, respectively.

The increase or decrease of the PCM absorption amount depends on the porous aggregates and PCM type. It can be stated that the percentage mass drop for the impregnated/coated LWAs with EV is related to the pore structure size (Fig. 4) of particles as well as their absorption capacity (Fig. 5). Additionally, it should be remarked that the weight losses of composites with respect to the leaked PCM after freeze/thaw cycles are less than $0.5 \%$ for different coating solutions (except in the cases with SIK waterproofing with slightly higher leaked PCM), which indicates that such coating/encasing materials minimizes the potential for leakage of the PCM. It should be stressed that, visual observation of the composites after testing confirmed that no leakage of the PCM was evident.

\subsection{Effect of oven drying test on weight drop percentage of composites}

The percentage weight loss of composites dried at $40{ }^{\circ} \mathrm{C}$ temperature was calculated with the same formula explained in the previous section. The weight drop values in percentage by mass were calculated for three different drying temperatures and the results for each composite are shown in Fig. 12.

Generally speaking, it can be observed in Fig. 12, that the leaked PCM percentage of mass loss in all the composites with waterproofing was less than $1 \%$ when composites are subjected to the drying temperature of $40^{\circ} \mathrm{C}$. Considering, when mass loss is less than $1 \%$, the potential for leakage of the PCM is minimum. Visual observation of the composites after testing confirmed that no leakage of the PCM occurred.

\section{Conclusions}

This paper assesses the thermal and physical aspects of lightweight aggregates (LWAs) incorporating phase change materials (PCMs), with the objective of improving freeze/thaw resistance of the studied composites, at material level. The study presents results from two different impregnated/encased PCMs in several LWA composites, namely: (i) a series containing paraffin PCM with melting temperature of $3^{\circ} \mathrm{C}$ (R3); (ii) a series containing paraffin PCM with melting temperature of $5^{\circ} \mathrm{C}$ (R5). These composites may prove advantageous for improving thermal resistance in pavements (reducing freeze/thaw cycles), and their feasibility at material/thermal/physical level was evaluated in this work. Experimental results, comprising a detailed analysis of the LWAs (particle density, absorption capacity of water and waterproofing material), as well as the performance of coated/impregnated LWAs under freeze/thaw cycles and exposure to high temperature are presented in this paper.

From the observation of particle density analysis, it was concluded that, expanded vermiculite (EV) has the greatest variation 
between the dry and saturated states among other types of LWAs. EV's pore structure analysis also revealed it has a highly porous matrix suitable for PCM impregnation when compared with other types of studied LWAs.

The observations of DSC thermograms pertaining to a consecutive heating load of testing on each PCM suggest that maximum specific enthalpy result was achieved for the R5. Therefore, R5 with specific enthalpy value nearly $180(\mathrm{~J} / \mathrm{g})$ has better potential of thermal energy storage than the other type of studied PCM (R3). Furthermore, it was found that tests with higher heating/cooling rates intensify the differences between the thermograms of the heating and cooling processes, both in terms of the peak temperatures and the overall shape of the curve. However, the calculated specific enthalpy for each phase transition seems to be independent of the heating/cooling rate.

From SEM analysis of the composite mortar it was concluded that, the IC particles were well coated with waterproofing material. The SEM investigation also revealed non-homogeneity of the waterproofing's thickness around the IC particles.

The influence of different waterproofing solutions on the weight loss of the composites under freeze/thaw cycles was analyzed, namely in terms of the weight drop percentage by mass as well as the amount of leaked PCM from the studied composites. Weight loss was found to be dependent on the used type of waterproofing materials. Since the waterproofing has potential of losing water content, thus, the issue related to the higher mass loss in the composites can be justified by the fact that, these composites are with thicker layer of waterproofing. Nevertheless, the amount of leaked PCM from different composites under freeze/thaw cycles were only up to $0.5 \%$, which indicated the fact of minimizes leakage of PCM from LWAs. Furthermore, visual observation confirmed that no leakage of the PCM occurred.

The observations from drying tests of the composites were also analogous to those already made for freeze/thaw test, confirming that, as expected, variation of weight loss percentages of the composites with and without waterproofing. However, an added analysis was made in regard to the waterproofing properties corresponding to the minimized PCM leakage. The influence of drying test has confirmed that, the waterproofing keeps its properties when drying temperature is $40^{\circ} \mathrm{C}$. However, there is a slightly higher weight drop percentage mass occurred when compared with the results from the freeze/thawing test.

It is finally remarked that the use of PCMs incorporated/encased in LWAs revealed adequate thermal behavior, as desirable outcome to reduce the freeze/thaw cycles effects under real climate conditions in pavement applications. Thus, this investigation carried out at material level confirms the feasibility of the proposed method for PCMs incorporation/encasement in LWAs. Furthermore, this methodology can be extended to building applications to increase thermal comfort. It may bring economic benefits due to the fact that some LWAs has the potential of high PCM absorption when compared with commercially available microencapsulated PCM products.

\section{Acknowledgments}

The authors acknowledge the funding given by Centre for Coordination and Regional Development Committee (CCDR-C) through the research project CENTRO-07-ST24_FEDER-002020 "Environmentally-Friendly Aeronautical Transport Systems Integrated Program (EFATRAS)", http://efatrasubi.wordpress.com. Supply of Expanded Clay materials by ARGEX - Argila Expandida, S.A and Cork materials by Sofalca - Sociedade Central de Productos de Cortiça, Lda are also acknowledged.

\section{References}

[1] Cabeza L, Castell A, Barreneche C, de Gracia A, Fernández A. Materials used as PCM in thermal energy storage in buildings: a review. Renew Sustain Energy Rev 2011;15(3):1675-95.

[2] Soares N, Costa JJ, Gaspar AR, Santos P. Review of passive PCM latent heat thermal energy storage systems towards buildings' energy efficiency. Energy Build 2013;59:82-103.

[3] Zhao CY, Zhang GH. Review on microencapsulated phase change materials (MEPCMs): fabrication, characterization and applications. Renew Sustain Energy Rev 2011;15(8):3813-32.

[4] Baetens A, Petter JB, Gustavsen A. Phase change materials for building applications: a state-of-the-art review. Energy Build 2010;42(9):1361-8.

[5] Waqas A, Zia UD. Phase change material (PCM) storage for free cooling of buildings-a review. Renew Sustain Energy Rev 2013;18:607-25.

[6] Vaz Sá A, Azenha M, de Sousa H, Samagaio A. Thermal enhancement of plastering mortars with phase change materials: experimental and numerical approach. Energy Build 2012;49:16-27.

[7] Kheradmand M, Aguiar JL, Azenha M. Estimation of the specific enthalpytemperature functions for plastering mortars containing hybrid mixes of phase change materials. Int J Energy Environ Eng 2014;81(5).

[8] Silva T, Vicente R, Soares N, Ferreira V. Experimental testing and numerical modelling of masonry wall solution with PCM incorporation: a passive construction solution. Energy Build 2012;49:235-45.

[9] Zhang YP, Lin KP, Yang R, Di HF, Jiang Y. Preparation, thermal performance and application of shape-stabilized PCM in energy efficient buildings. Energy Build 2006;38(10):1262-9.

[10] Ling T-C, Poon C-S. Use of phase change materials for thermal energy storage in concrete: an overview. Constr Build Mater 2013;46:55-62.

[11] Ma B, Adhikari S, Chang Y, Ren J, Liu J, You Z. Preparation of composite shapestabilized phase change materials for highway pavements. Constr Build Mater 2013;42:114-21.

[12] Gowreesunker BL, Tassou SA. Effectiveness of CFD simulation for the performance prediction of phase change building boards in the thermal environment control of indoor spaces. Build Environ 2013;59:612-25.

[13] Sakulich AR, Bentz DP. Incorporation of phase change materials in cementitious systems via fine lightweight aggregate. Constr Build Mater 2012;35:483-90.

[14] Sakulich A, Bentz D. Increasing the service life of bridge decks by incorporating phase-change materials to reduce freeze-thaw cycles. J Mater Civ Eng 2012;24(8):1034-42.

[15] Nepomuceno MCS, Silva PD. Experimental evaluation of cement mortars with phase change material incorporated via lightweight expanded clay aggregate. Constr Build Mater 2014;63:89-96.

[16] Zhang Z, Shi G, Wang S, Fang X, Liu X. Thermal energy storage cement mortar containing n-octadecane/expanded graphite composite phase change material. Renew Energy 2013;50:670-5.

[17] Xu B, Li Z. Paraffin/diatomite composite phase change material incorporated cement-based composite for thermal energy storage. Appl Energy 2013;105:229-37.

[18] Li X, Sanjayan JG, Wilson JL. Fabrication and stability of form-stable diatomite/paraffin phase change material composites. Energy Build 2014;76:284-94.

[19] Mehrali M, Tahan Latibari S, Mehrali M, Mahlia TMI, Cornelis Metselaar HS. Effect of carbon nanospheres on shape stabilization and thermal behavior of phase change materials for thermal energy storage. Energy Convers Manage 2014;88:206-13.

[20] Qi G-Q, Liang C-L, Bao R-Y, Liu Z-Y, Yang W, Xie B-H, et al. Polyethylene glycol based shape-stabilized phase change material for thermal energy storage with ultra-low content of graphene oxide. Sol Energy Mater Sol Cells 2014;123:171-7.

[21] Trigui A, Karkri M, Krupa I. Thermal conductivity and latent heat therma energy storage properties of LDPE/wax as a shape-stabilized composite phase change material. Energy Convers Manage 2014;77:586-96.

[22] Li H, Chen H, Li X, Sanjayan JG. Development of thermal energy storage composites and prevention of PCM leakage. Appl Energy 2014;135: 225-33.

[23] He Y, Zhang X, Zhang Y. Preparation technology of phase change perlite and performance research of phase change and temperature control mortar. Energy Build 2014;85:506-14.

[24] Sar1 A, Karaipekli A. Preparation, thermal properties and thermal reliability of capric acid/expanded perlite composite for thermal energy storage. Mater Chem Phys 2008;109(2-3):459-64.

[25] RUBITHERM GmbH, Technologies GmbH thermal challenges with PCMTechnology, Germany; 2013.

[26] Zhang D, Zhou J, Wu K, Li Z. Granular phase changing composites for thermal energy storage. Sol Energy 2005;78(3):471-80.

[27] Pires L, Silva PD, Castro Gomes JP. Experimental study of an innovative element for passive cooling of buildings. Sustain Energy Technol Assessments 2013;4:29-35.

[28] ARGEX - Argila Expandida, S.A., National structural ceramics, Technical sheet for ARGILA EXPANDIDA, Portugal; 2013.

[29] GALO BRANCO - Produções and Construções Ecológicas LDA, Edisol Group, Agglomerates of expanded cork products, Portugal; 2014.

[30] The URBICULT Unipessoal Co. - Vermiculite/Perlite products, Portugal; 2012. 
[31] Karaipekli A, Sarı A. Capric-myristic acid/vermiculite composite as form-stable phase change material for thermal energy storage. Sol Energy 2009;83(3): $323-32$.

[32] Lu Z, Xu B, Zhang J, Zhu Y, Sun G, Li Z. Preparation and characterization of expanded perlite/paraffin composite as form-stable phase change material. Sol Energy 2014;108:460-6.

[33] Nóvoa PJRO, Ribeiro MCS, Ferreira AJM, Marques AT. Mechanical characterization of lightweight polymer mortar modified with cork granulates. Compos Sci Technol 2004;64(13-14):2197-205.

[34] CSN EN 933-1:2012, Tests for geometrical properties of aggregates - Part 1: determination of particle size distribution - Sieving method; 2012

[35] SIKA Group. - Technical sheet for Sikalastic -490T, Version No. 1, Portugal; 2012.

[36] Weber SAINT-GOBAIN - Leading industrial mortar manufacturer, Technical sheet for Weber Dry Lastic, Portugal; 2009.

[37] MC-Bauchemie - Building chemical products, Technical data sheet for Makote 3, Portugal; 2013.

[38] CEPSA (Compañía Española de Petróleos, S.A.U.) - Waterproofing and soundproofing products, Technical sheet for ECM-2 (C67BF4), Version No. 5 , Portugal; 2010.

[39] NP EN 1097-6:2013, Tests for mechanical and physical properties of aggregates - Part 6: determination of particle density and water absorption; 2013.

[40] User manual NOVA WIN. Quantachrome Instruments, Nova Series Windowsbased operating and data 2008.

[41] Castellon C, Gunther E, Mehling H. Determination of the enthalpy of PCM as a function of temperature using a heat-flux DSC, a study of differen measurement procedures and their accuracy. J Energy Res 2008;32:1258-65.

[42] Kheradmand M, Azenha M, De Aguiar JLB, Krakowiak KJ. Thermal behavior of cement based plastering mortar containing hybrid microencapsulated phase change materials. Energy Build 2014;84:526-36.
[43] Biwan Xu, Li Zongjin. Paraffin/diatomite composite phase change material incorporated cement-based composites for thermal energy storage. Appl Energy 2013;105:229-37.

[44] Melhing H, Cabeza LF. In: Dieter Mewes, editor. Heat and cold storage with PCM, an up to date introduction into basics and applications. Berlin, Germany: Springer; 2008.

[45] Denner T. NETZSCH Proteus - thermal analysis - release 6.0.0, Gerätebau GmbH Wittelsbacherstraße 42; 2012.

[46] EN ISO 11357-1. Plastics - differential scanning calorimetry (DSC) part 1: general principles. Berlin: DIN Deutsches Institut für Normung e.V.; 1997.

[47] The World Weather Online, Global weather forecast and weather content for websites, businesses and the travel industry, <http://www.worldweather online.com/>. Retrieved 2014

[48] Castro J, Keiser L, Golias M, Weiss J. Absorption and desorption properties of fine lightweight aggregate for application to internally cured concrete mixtures. Cement Concr Compos 2011;33(10):1001-8.

[49] Collins F, Sanjayan JG. Effect of pore size distribution on drying shrinking of alkali-activated slag concrete. Cem Concr Res 2000;30(9):1401-6.

[50] Jin X, Xu X, Zhang X, Yin Y. Determination of the PCM melting temperature range using DSC. Thermochim Acta 2014;595:17-21.

[51] Dumas J-P, Gibout S, Zalewski L, Johannes K, Franquet E, Lassue S, et al. Interpretation of calorimetry experiments to characterise phase change materials. Int J Therm Sci 2014;78:48-55.

[52] Kousksou T, Jamil A, Zeraouli Y. Enthalpy and apparent specific heat capacity of the binary solution during the melting process: DSC modelling. Thermochim Acta 2012;41:31-41.

[53] Kousksou T, Rhafiki T, Jamil A, Bruel P, Zeraouli Y. PCMs inside emulsions: some specific aspects related to DSC (differential scanning calorimeter)-like configurations. Energy 2013;56:175-83. 